\title{
Occurrence of methicillin-resistant Staphylococcus aureus in dairy cattle herds, related swine farms, and humans in contact with herds
}

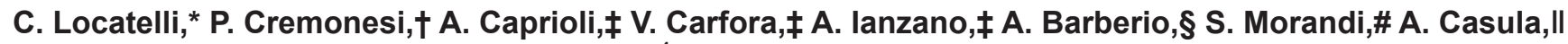 \\ B. Castiglioni, $\dagger$ V. Bronzo, Il and P. Moronill $\|^{1}$ \\ *Dipartimento di Scienze Veterinarie per la Salute, la Produzione Animale e la Sicurezza Alimentare, Università degli Studi di Milano, \\ 20133 Milan, Italy \\ †Istituto di Biologia e Biotecnologia Agraria, (IBBA-CNR), via Einstein, 26900 Lodi, Italy \\ ‡lstituto Zooprofilattico Sperimentale del Lazio e della Toscana "M. Aleandri" General Diagnostic Department, \\ National Reference Laboratory for Antimicrobial Resistance, Via Appia Nuova 1411, 00178 Rome, Italy \\ §Istituto Zooprofilattico Sperimentale delle Venezie, Vicenza viale Fiume 78, 36100 Vicenza, Italy \\ \#Istituto di Scienze delle Produzioni Alimentari, (ISPA-CNR), via Celoria 2, 20133 Milan, Italy \\ IIDipartimento di Medicina Veterinaria, Università degli Studi di Milano, 20133 Milan, Italy \\ IAnimal Heath Diagnostic Center, Quality Milk Production Services, Cornell University, Ithaca, NY 14853
}

\section{ABSTRACT}

In this study we investigated the circulation of methicillin-resistant Staphylococcus aureus (MRSA) in 2 dairy cattle farms (farm A and B), previously identified as MRSA-positive in bulk tank milk samples, and epidemiologically related to swine farms. Collected specimens included quarter milk samples and nasal swabs from dairy cows, pig nasal swabs collected at both the farm and slaughterhouse level, environmental dust samples, and human nasal swabs from the farms' owners and workers. The prevalence of MRSA was estimated at the herd level by testing quarter milk samples. The prevalence of MRSA was 4.8\% (3/63; 95\% confidence interval $=0-10.2 \%)$ and $60 \%(33 / 55 ; 95 \%$ confidence interval $=$ 47.05-72.95) in farm A and B, respectively. In farm A, MRSA was also isolated from humans, pigs sampled at both farm and slaughterhouse level, and from environmental samples collected at the pig facilities. The dairy cattle facilities of farm A tested negative for MRSA. In farm B, MRSA was isolated from environmental dust samples in both the cattle and pig facilities, whereas nasal swabs collected from cows and from humans tested negative. Sixty-three selected MRSA isolates obtained from different sources in farm A and B were genetically characterized by multilocus sequence typing, spa-typing, ribosomal spacer-PCR, and also tested for the presence of specific virulence genes and for their phenotypical antimicrobial susceptibility by broth microdilution method. Different clonal complex (CC) and spa-types were identified, including CC398, CC97, and $\mathrm{CC} 1, \mathrm{CC}$ already reported in livestock animals in Italy. The MRSA isolates from quarter milk of farm A and

Received July 29, 2016.

Accepted September 25, 2016.

${ }^{1}$ Corresponding author: paolo.moroni@unimi.it
B mostly belonged to CC97 and CC398, respectively. Both lineages were also identified in humans in farm A. The CC97 and CC398 quarter milk isolates were also identified as genotype GTBE and GTAF by ribosomal spacer-PCR respectively, belonging to distinct clusters with specific virulence and resistance patterns. The GTBE and GTAF clusters also included swine, environmental, and human isolates from both farms. A high heterogeneity in the genetic and phenotypic profiles was observed in environmental isolates, in particular from farm B. These results demonstrate the possibility of a dynamic sharing and exchange of MRSA lineages or genotypes between different species and farm compartments in mixed-species farms. The risk of transmission between swine and related dairy cattle herds should be considered. Our findings also confirm the zoonotic potential of livestock-associated MRSA and underline the importance of applying biosecurity measures and good hygiene practices to prevent MRSA spread at the farm level and throughout the food production chain.

Key words: dairy cow, pig, methicillin-resistant Staphylococcus aureus, molecular typing, zoonosis

\section{INTRODUCTION}

The emergence of livestock-associated (LA) methicillin-resistant Staphylococcus aureus (MRSA) among and within livestock species is a relevant issue from both human and animal health perspectives (Voss et al., 2005). Currently, clonal complex (CC) 398, including several spa-types, is the most prevalent LA-MRSA lineage in Europe and, although it does not have a high host specificity, it is mainly found as a nasal colonizer of pigs in countries with a high density of swine farms (EFSA, 2010). In Italy, other major LA-MRSA lineages, such as $\mathrm{CC} 1$ and $\mathrm{CC} 97$, have also been found to colonize and cause infection in livestock (Alba et al., 
2015; Feltrin et al., 2015; Luini et al., 2015; Carfora et al., 2016). Zoonotic transmission of LA-MRSA strains from livestock to humans, with subsequent severe infections, have been reported (Soavi et al., 2010; Lozano et al., 2011). Moreover, it has been demonstrated that people living and working in close contact with farm animals are particularly exposed to MRSA colonization (van Loo et al., 2007; Van den Broek et al., 2009; Van Cleef et al., 2011; Carfora et al., 2016), possibly contributing to the MRSA spread throughout the food chain (Kluytmans, 2010; Wendlandt et al., 2013).

Livestock-associated MRSA can colonize the udder and cause IMI in dairy ruminants (Cortimiglia et al., 2015; Luini et al., 2015; Carfora et al., 2016), sometimes leading to clinical mastitis (CM) and relevant economic losses (Feßler et al., 2010; Vanderhaeghen et al., 2010). However, the epidemiology of MRSA in dairy cattle is yet to be fully investigated and the rate of the infection is not clear (Vanderhaeghen et al., 2010). A high variability of inter-herd (Haran et al., 2012; Kreausukon et al., 2012; Paterson et al., 2012) and intra-herd (Vanderhaeghen et al., 2010; Feßler et al., 2012; Luini et al., 2015) prevalence has been reported so far. Moreover, on the base of the genetic relatedness observed among isolates detected from different sources, different patterns of transmission between and within investigated farms have been described (Feßler et al., 2012). In a previous study (Locatelli et al., 2016), we demonstrated a clear exposure-response relationship between the number of swine and swine herds present in a territory with the MRSA status of dairy cattle herds. Moreover, it has been already demonstrated that environmental dust carried by the wind or contaminated items can act as a passive MRSA spreader (Friese et al., 2012; Merialdi et al., 2013), allowing a possible transmission between swine and close-proximity dairy herds.

The aims of the current work were (1) to assess the presence of MRSA in individual quarter milk samples from 2 dairy farms of northern Italy previously identified as MRSA-positive and geographically or epidemiologically related to swine farms; (2) to investigate the MRSA circulation by testing environmental, human, and swine specimens from the same farms; (3) to characterize the MRSA isolated from different sources by molecular methods; and (4) to evaluate the genetic relatedness of the MRSA isolates and to hypothesize possible dynamics of transmission.

\section{MATERIALS AND METHODS}

\section{MRSA-Positive Farm Characteristics}

The study was carried out in 2 dairy farms (farm A and B) located in northern Italy. In March 2010, a survey was performed to assess the presence of MRSA in dairy cattle herds located in a highly productive area of northern Italy. Bulk tank milk samples from 27 dairy farms were collected and analyzed at the laboratory of the Department of Health, Animal Science and Food Safety, University of Milan, as previously described (Locatelli et al., 2016). At that time, 2 different farms, named farm $\mathrm{A}$ and $\mathrm{B}$, were found to be positive for MRSA. The studied dairy farms were not epidemiologically related, were located in different municipalities, had no exchange of living animals, and had no common workers or veterinarians. Both farms were geographically or epidemiologically related to swine facilities. In both cases, pig and dairy cattle facilities were situated within less than $100 \mathrm{~m}$ and the farms shared the same service passages, without any physical division.

Farm A included dairy and pig herds in close proximity, although 2 different owners managed these activities. The dairy herd comprised 180 lactating cows, milked twice a day and reared in freestall facilities. The swine herd was a farrow-to-finish herd consisting of 3,135 animals. The 2 owners and 2 employees represented all the staff. The cattle owner (owner 1) managed the dairy herd and normally milked twice daily, helped by an employee milker. The milking routine procedures included wearing disposable gloves, predipping followed by cleaning with paper wipes, and postdipping. The manager of the swine herd (owner 2) was also occasionally involved in all the other activities within the family property, including daily milking procedures.

Farm B included 55 lactating cows reared in freestall facilities and the farmers (father and son) milked twice a day. They did not use gloves and applied only a postmilking teat dip. The swine facility was located close by and was a finishing unit composed of 5 barns harboring about 4,000 fattening pigs. The swine unit was managed by a third person, whereas a caretaker, living nearby, was entrusted with the feeding operations and animal care. The owners of the dairy cows and the swine caretaker had free access to the whole external area outside both farms, without any restriction.

\section{Samples Collection and MRSA Identification}

Between April and July 2010, quarter milk samples, animal and human nasal swabs, and environmental dust samples were collected from the 2 dairy farms and the respective neighboring swine farms. All samples were analyzed at the laboratory of the Department of Health, Animal Science and Food Safety of the University of Milan. The owners voluntarily accepted to participate to the survey, but agreed to sample only part of the animals. 
Quarter Milk Samples. Farm A owners allowed sampling of one-third of the dairy herd $(\mathrm{n}=63)$, and eligible cows were selected from 3 groups representative of the herd. Group $1(\mathrm{n}=23)$ included cows with high SCC (>200,000 cells $/ \mathrm{mL})$ at the last DHI control, group $2(\mathrm{n}=19)$ included fresh cows with less than 90 DIM, and group $3(\mathrm{n}=21)$ included cows in mid lactation with $>120$ DIM. A total of 244 quarter milk samples were collected. In farm B, all lactating cows $(\mathrm{n}=55)$ were sampled for a total of 211 milk samples from functional quarters.

At sampling, teat ends were carefully cleaned and disinfected with chlorhexidine and $70 \%$ alcohol. After the discharge of the first streams of foremilk, approximately $10 \mathrm{~mL}$ of individual quarter milk samples were collected into sterile vials. Samples were refrigerated at $4^{\circ} \mathrm{C}$, shipped and transported to the laboratory within few hours after collection, and frozen at $-20^{\circ} \mathrm{C}$ until bacteriological analyses. Milk samples were processed and pathogens identified according to the National Mastitis Council guidelines (NMC, 1999). Briefly, 10 $\mu \mathrm{L}$ of each milk sample were spread on one-quarter of a 5\% sheep blood agar plate (Merck, Darmstadt, Germany). Plates were incubated aerobically at $37^{\circ} \mathrm{C}$ and examined at 24 and $48 \mathrm{~h}$. Presumptive colonies were provisionally identified based on Gram staining, morphology, and hemolytic pattern. Staphylococcus spp. suspected colonies were further tested by coagulase tube test (Istituto Zooprofilattico Sperimentale delle Venezie, Padova, Italy).

All the coagulase-positive colonies were streaked onto Mueller-Hinton agar (Merck) with $6 \mu \mathrm{g} / \mathrm{mL}$ of oxacillin and $4 \% \mathrm{NaCl}$ (Sigma-Aldrich, Schnelldorf, Germany; Corrente et al., 2007). Oxacillin-resistant colonies were also tested for their susceptibility to cefoxitin $(30 \mu \mathrm{g}$ disk content; Biomerieux, Marcy L'Étoile, France) by the disk diffusion method, according to the criteria of CLSI $(2013 \mathrm{a}, \mathrm{b})$. Results were interpreted following the performance standards for antimicrobial susceptibility testing (CLSI, 2013b).

All the cefoxitin-resistant colonies were tested for Staphylococcus aureus and MRSA confirmation by using a duplex PCR including primers targeting the mecA (Murakami et al., 1991) and the nuc gene (Baron et al., 2004) in a single PCR reaction. A second PCR assay was performed by using primers targeting the variant $m e c C$ according to Paterson et al. (2012). Isolates were inoculated in brain heart infusion (Laboratorios Conda, Madrid, Spain) and cultured overnight at $37^{\circ} \mathrm{C}$, and then DNA were extracted using a commercial extraction kit (RBC Bioscience, New Taipei City, Taiwan) according to the manufacturer's instructions. Staphylococcus aureus ATCC 33592 was included in each PCR reaction as a control strain. All the MRSA were stored in nutrient broth (Pronadisa, Madrid, Spain) with 15\% glycerol at $-80^{\circ} \mathrm{C}$ for subsequent analyses.

Nasal Swabs and Environmental Samples. During the visit to farm A, environmental dust samples (n $=6)$ as well as swine $(\mathrm{n}=2)$ and human nasal swabs $(\mathrm{n}=4)$ were collected. On the dairy farm, dust samples were collected from 3 different sites, representative of the lactating cow barns (at the 2 ends and in the middle of the main row) and from milking parlor $(\mathrm{n}=1)$. Similarly, in the swine facilities dust samples were collected from each barn $(\mathrm{n}=2)$. Nasal swabs from 2 finishing pigs were collected at the farm just before sending the animals to the slaughterhouse. Thirty-three individual nasal swabs, out of a batch of 130 pigs, were also collected at the slaughterhouse soon after stunning. $\mathrm{Hu}-$ man nasal swabs were self-taken on a voluntary basis by the 2 owners and the 2 employees.

On farm B, dust samples were collected from each swine barn $(\mathrm{n}=5)$, from the dairy cattle stall barn ( $\mathrm{n}$ $=1$ ), and from the milking parlor $(\mathrm{n}=1)$. The owners also agreed to collect nasal swabs from 15 out of 55 lactating cows and from the farm dog. However, the collection of nasal swabs from pigs was not permitted by the swine caretaker. Human nasal swabs $(\mathrm{n}=2)$ were self-administered on a voluntary basis by the 2 dairy cattle owners only.

All dust samples were collected by sterile gauze and kept in sterile plastic stomacher bags until processing. Human and pig nasal samples were collected using cotton-tipped swabs kept in Amies transport medium (Copan, Brescia, Italy). All samples were stored at $4^{\circ} \mathrm{C}$ and processed within $24 \mathrm{~h}$. Nasal swabs $(\mathrm{n}=56)$ and dust samples $(\mathrm{n}=13)$ were processed using a 2-step enrichment procedure as previously described (Spohr et al., 2011). One hundred microliters of the final resulting broth was plated onto MRSA Chromogenic Agar (Pronadisa) and incubated for $48 \mathrm{~h}$ at $37^{\circ} \mathrm{C}$. At least 5 blue-greenish colonies were picked up and cultured on 5\% sheep blood agar (Pronadisa). Confirmation of MRSA was performed by PCR as described above for the milk isolates. All the MRSA were stored in Nutrient Broth (Pronadisa) with $15 \%$ glycerol at $-80^{\circ} \mathrm{C}$ for subsequent analyses.

\section{MRSA Characterization}

Isolates Selection. A panel of 57 MRSA isolates collected during the April to July 2010 survey, and representative of the different sources sampled in farms $\mathrm{A}$ and $\mathrm{B}$, were selected for molecular characterization and antimicrobial susceptibility testing. Regarding individual milk samples, due to the few positive animals 
detected on farm A, all the MRSA isolates obtained from quarter milk samples were included in the analyses. For farm B, isolates were selected from single quarter milk samples of animals considered representative of the herd on the basis of specific parameters (parity, milk yield, DIM, and SCC). Multiple isolates (up to 6 per plate) from MRSA-positive nasal swabs and dust samples were included because of the composite nature of these samples. Two MRSA milk isolates detected at farm A in 2008 from cases of CM (isolates 2256 and 2302) and 4 isolates from bulk tank milk samples collected at farm A in March 2010 were also included in the analysis to evaluate the lineages persistence over the time.

Molecular Typing. Selected MRSA isolates $(\mathrm{n}=$ 63) were screened by using a specific PCR for the identification of CC398, according to Stegger et al. (2011) and further genotyped by spa-typing as described by Battisti et al. (2010). Representative non-CC398 isolates were further genotyped by multilocus sequence typing (Battisti et al., 2010).

A 16S-23S rRNA intergenic spacer genotyping PCR (RS-PCR) was performed, as previously described by Cremonesi et al. (2015) on the same 63 isolates. The PCR products were analyzed using an Agilent 2100 Bioanalyzer with a DNA 7500 LabChip kit (Agilent Technologies, Palo Alto, CA). For the interpretation of the results, 2 patterns were considered different if 2 or more peaks of the electropherogram differed in size. Grouping of the RS-PCR profiles was obtained with the BioNumerics 5.0 software package (Applied Maths, Sint-Martens-Latem, Belgium), using the UPGMA (unweighted pair group method) cluster analysis. Genotypes were further defined according to the method by Fournier et al. (2008), improved by calculating the corresponding Mahalanobis distance of informative peak sizes, and by comparing it to those of the prototype strains using the Mahalanobis distances of $S$. aureus Genotypes software (Syring et al., 2012). The isolates that did not match with any prototype strain were classified as ni (not identified). Based on the RSPCR profiles, a dendrogram was constructed using the BioNumerics software (Figure 1). All the selected MRSA isolates from farm $\mathrm{A}$ and $\mathrm{B}$ were included to evaluate possible relatedness, both within and between farms. Within the 2 main branches, clusters and subclusters were considered according to cutoff values of 80 and $90 \%$ of similarity, respectively.

Virulence Genes Detection. The MRSA isolates were further screened for the presence of virulencetarget genes using the panel of primers and protocols described by Cremonesi et al. (2013). Screening searched for 7 selected staphylococcal enterotoxin (SE) genes (sea, seb, sec, see, seg, seh, sei) and 3 selected staphylococcal-like (SEl) protein genes (selj, selk, sel); exotoxin genes, including those coding the exfoliative toxins A and B (eta and etb) and the toxic shock syndrome toxin 1 gene (tsst); the genes coding the components of leukocidin E (lukE), leukocidins E and D (LukE-LukD); and the Panton-Valentine (PV) leukocidin components $\mathrm{S}$ and $\mathrm{F}(L u k F / S-P V)$. The presence of immune evasion cluster genes, including the chemotaxis inhibitory protein $(c h p)$, staphylokinase $(s a k)$, and staphylococcal complement inhibitor (scn), coding genes, and those coding 3 adhesion factors, including the clumping factor A (clfA), collagen binding protein (cna) and fibronectin binding protein $(f m t B)$, was also investigated.

\section{Antimicrobial Susceptibility Testing}

The MRSA isolates were tested for their antimicrobial susceptibility by broth micro-dilution method (Sensititer, Trek Diagnostics System, East Grinstead, UK), according to the procedure described in CLSI (2013a). The following antimicrobials tested were ampicillin, amikacin, cefoxitin, gentamicin, clindamycin, tetracycline, rifampin, enrofloxacin, and erythromycin. The sensititer plate reading was performed manually, recording the last concentration of the antimicrobials without turbidity or deposit of cells at the bottom of the well. Staphylococcus aureus ATCC 29213 was used as a quality-control strain. Results for minimum inhibitory concentrations were interpreted according to the CLSI (2013b) resistance breakpoints for Staphylococcus spp.

\section{RESULTS}

\section{MRSA in Quarter Milk Samples}

On farm A, out of 244 quarter milk samples tested, 6 S. aureus isolates were obtained from 4 different cows, whereas on farm B, out of 211 samples tested, $S$. aureus was isolated from 62 quarter milk samples from 33 dairy cows (Table 1 ). With the exception of 1 isolate from farm A, $67 \mathrm{~S}$. aureus isolates grew on the oxacillin-added Mueller-Hinton agar and were resistant to cefoxitin. All the cefoxitin-resistant isolates tested positive for the nuc and the mecA genes, and negative for the mecC gene. On farm A, the estimated MRSA prevalence at the herd and quarter levels were $4.8 \%$ $(3 / 63 ; 95 \% \mathrm{CI}=0-10.2 \%)$ and $2.1 \%(5 / 244 ; 95 \% \mathrm{CI}$ $=0.27-3.83)$, respectively, whereas on farm $\mathrm{B}$ they were $60 \%(33 / 55 ; 95 \% \mathrm{CI}=47.05-72.95)$ and $28.2 \%$ $(62 / 211 ; 95 \%$ CI $=23.24-35.53 \%)$, respectively. 


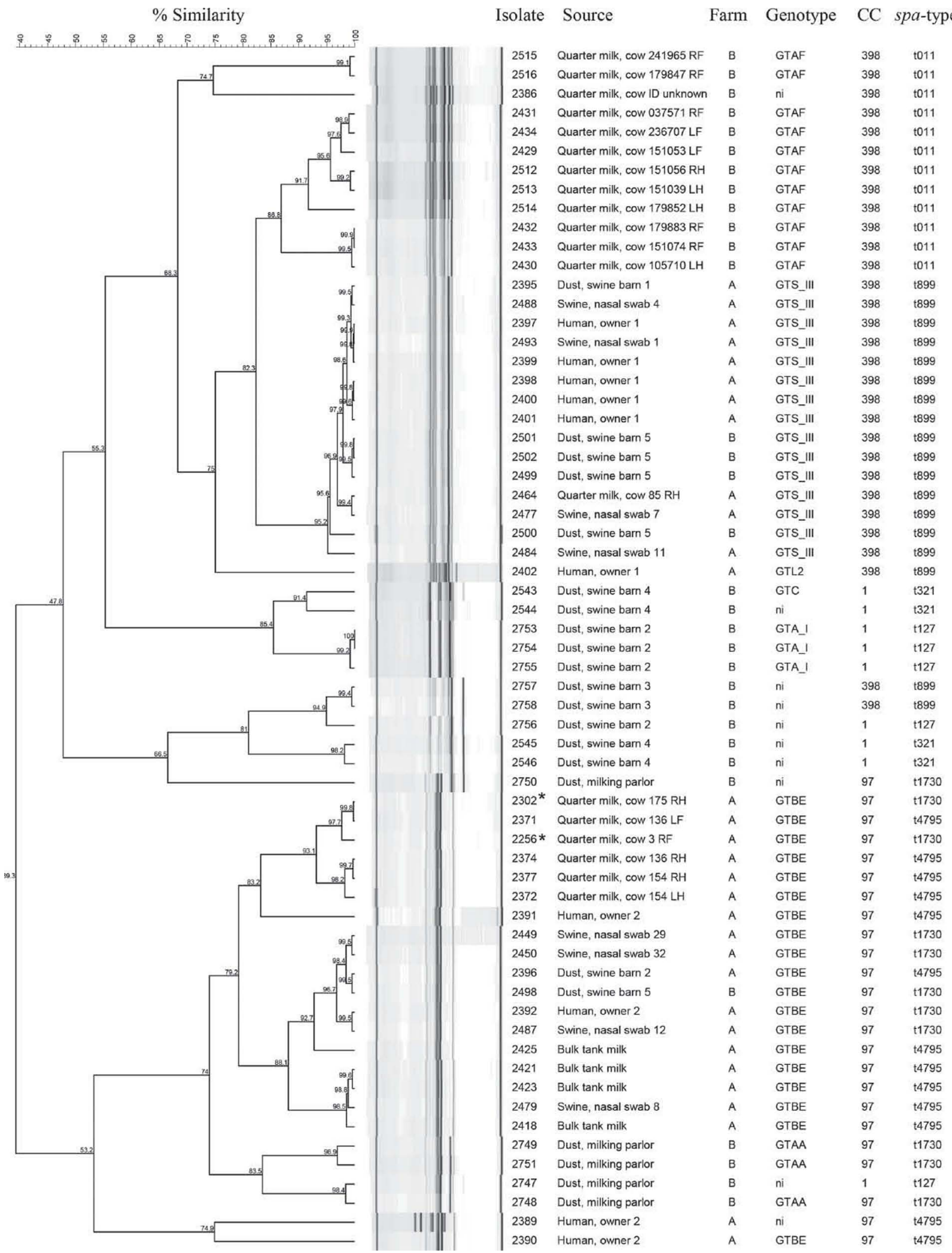

Figure 1. Unweighted pair-group method with arithmetic averages (UPGMA)-based dendrogram derived from ribosomal spacer (RS)-PCR analyses of all the selected isolates. The graphic shows the relatedness between isolates from both farms and all sources. Identification, specific source, farm, genotype, clonal complex (CC) and spa-type are reported for each isolate. Isolate 2256 and $2302(*)$ were detected in 2008 . LF $=$ left front quarter; $\mathrm{RF}=$ right front quarter; $\mathrm{RH}=$ right hind quarter; $\mathrm{LH}=$ left hind quarter; ni $=$ not identified. 


\section{MRSA in Nasal Swabs, and in Environmental Samples}

On farm A MRSA was isolated from the nasal swabs of both owners, but not from the 2 workers tested, including the milker. We also isolated MRSA from 1 of the 2 pigs sampled at farm level and from 15 out of the 33 individual nasal swabs collected from pigs at slaughter. The 2 dust samples collected from the 2 pig barns were also MRSA-positive, whereas those collected from the milking parlor and from the dairy cattle facilities tested negative (Table 1).

On farm B the environmental dust samples from the 5 swine barns and from the milking parlor facilities were MRSA-positive. Conversely, the nasal swabs collected from 15 lactating cows, the cattle owners, the farm dog, and the dust samples collected from the dairy cattle facilities resulted negative for MRSA (Table 1). All the isolates were mecA-positive and $m e c C$-negative.

\section{MRSA Characterization}

Sixty-three MRSA isolates were selected for molecular characterization, 31 from farm A and 32 from farm B (Table 1). Selected isolates included 19 from quarter milk samples, 7 from farm A (including the 2 strains isolated in 2008 from $\mathrm{CM}$ ) and 12 from farm B; 4 from bulk tank milk samples collected in farm A during the preliminary survey; 22 from dust samples, 2 from farm A and 20 from farm B; 8 from nasal swabs of pigs sampled in farm A; and 10 from human nasal swabs of the 2 owners of farm A. Regarding quarter milk samples, on farm A MRSA isolates were selected from the positive quarters $(\mathrm{n}=5)$ of the only 3 positive cows, whereas on farm B isolates were selected from 12 single quarter milk samples of 12 positive animals considered representative of the herd.

The results of spa-typing, RS-PCR, CC grouping, detection of virulence target genes, and antimicrobial susceptibility testing for the selected isolates from farm $\mathrm{A}$ and $\mathrm{B}$ are reported in Tables 2 and 3, respectively. Overall, 3 different CC (CC1, CC97, and CC398) and 6 different spa-types (t011, t127, t1730, t321, t4795, and t899) were identified among the MRSA isolated from the 2 farms.

The RS-PCR generated 7 coded genotypes, grouping 53 out of the 63 selected MRSA. The GTBE genotype was the most represented $(\mathrm{n}=19)$, followed by GTS ${ }^{\text {III }}$ $(\mathrm{n}=15), \operatorname{GTAF}(\mathrm{n}=11)$, GTAA $(\mathrm{n}=3)$, and $\mathrm{GTA}^{\mathrm{I}}$ $(\mathrm{n}=3)$, with GTC and GTL2 each having a single isolate. The remaining 10 isolates showed 7 different profiles and were classified as ni (not identified). These 10 isolates were from 1 human swab from farm A, 1 milk sample and from 8 dust sample, collected from swine barns $(\mathrm{n}=6)$ and milking parlor facilities $(\mathrm{n}=$ 2) in farm B.

Most of the isolates were negative for enterotoxin genes. On farm B, 10 isolates tested positive for the seh gene: $8 \mathrm{CC} 1$ isolates obtained from the dust samples of swine barns 2 and 4, $1 \mathrm{CC} 1$ obtained from the dust samples of the milking parlor, and 1 isolate from swine barn 5. Another farm B isolate (2758), detected from

Table 1. Samples collected per source and per farm, number of methicillin-resistant Staphylococcus aureus (MRSA)-positive samples, and number of MRSA isolates selected for molecular typing

\begin{tabular}{|c|c|c|c|c|c|c|}
\hline $\begin{array}{l}\text { Farm } \\
\text { ID }\end{array}$ & Source & $\begin{array}{l}\text { Time of } \\
\text { sampling }\end{array}$ & $\begin{array}{l}\text { No. of samples } \\
\text { collected/individuals } \\
\text { or facilities sampled }\end{array}$ & $\begin{array}{l}\text { No. of } \\
\text { MRSA-positive } \\
\text { samples }\end{array}$ & $\begin{array}{l}\text { No. of } \\
\text { MRSA } \\
\text { isolated }\end{array}$ & $\begin{array}{c}\text { No. of } \\
\text { selected MRSA } \\
\text { isolates }\end{array}$ \\
\hline \multirow[t]{6}{*}{ A } & $\begin{array}{l}\text { Quarter milk samples from clinical } \\
\text { mastitis }^{1}\end{array}$ & 2008 & $2 / 2$ & 2 & 2 & 2 \\
\hline & Bulk tank milk samples ${ }^{2}$ & March 2010 & $9 / 1$ & 3 & 9 & 4 \\
\hline & Quarter milk samples & 2010 & $224 / 63$ & 5 (from 3 cows) & 5 & 5 \\
\hline & Human nasal swabs & 2010 & $4 / 4$ & 2 & 12 & 10 \\
\hline & Dust from swine barns & 2010 & $2 / 2$ & 2 & 2 & 2 \\
\hline & Swine nasal swabs & 2010 & $35 / 35$ & 18 & 25 & 8 \\
\hline \multirow[t]{5}{*}{ B } & Quarter milk samples & 2010 & $211 / 55$ & 62 (from 33 cows) & 62 & 12 \\
\hline & Human nasal swabs & 2010 & $2 / 2$ & None & - & - \\
\hline & Bovine nasal swabs & 2010 & $15 / 15$ & None & - & - \\
\hline & Dust from dairy cow facilities & 2010 & 1 & None & - & - \\
\hline & Dust from milking parlor & 2010 & 1 & 1 & 6 & 5 \\
\hline
\end{tabular}

${ }^{1}$ S. aureus isolated in 2008 but further characterized in 2010.

${ }^{2}$ Samples collected in March 2010 during the preliminary investigations. 


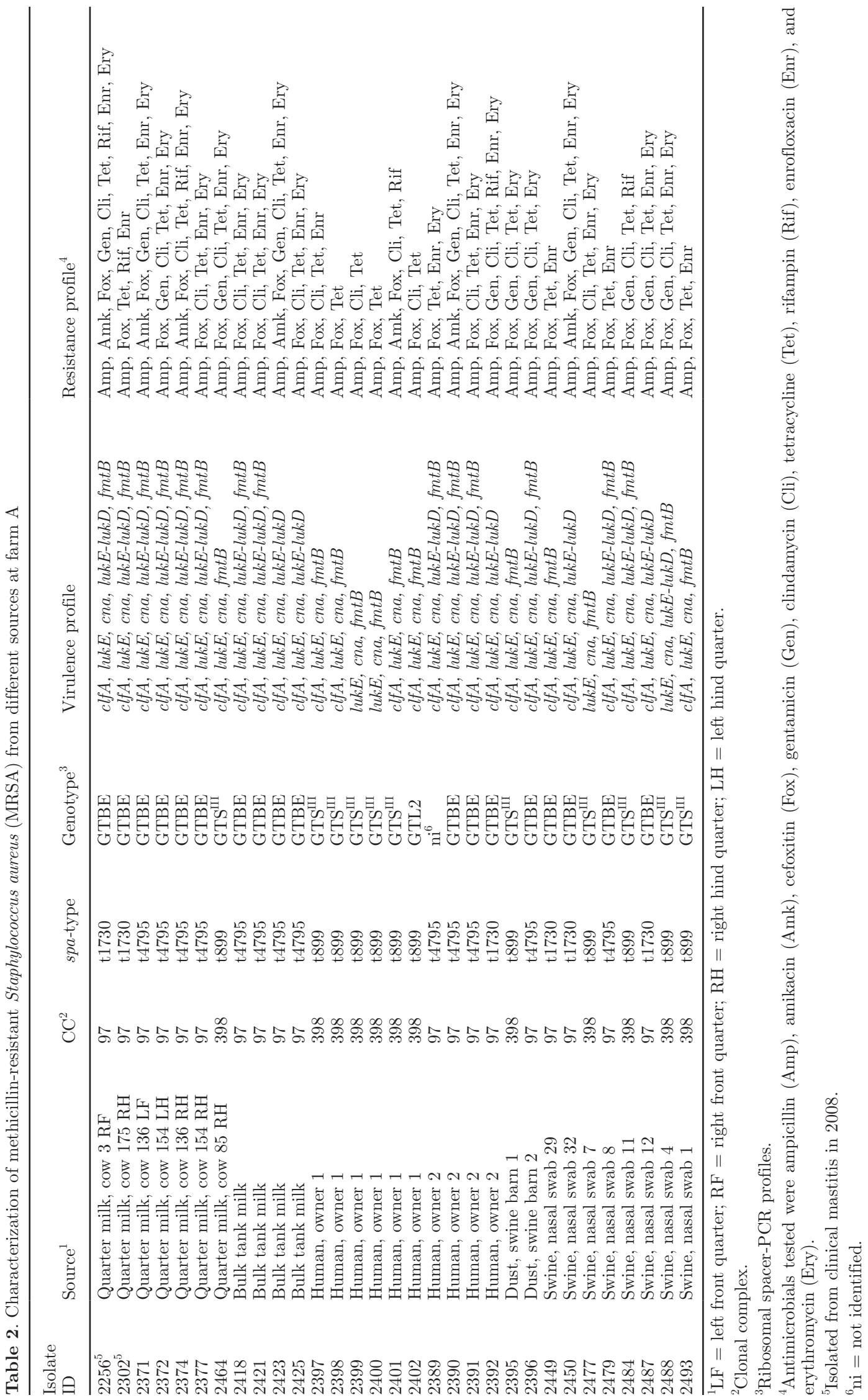




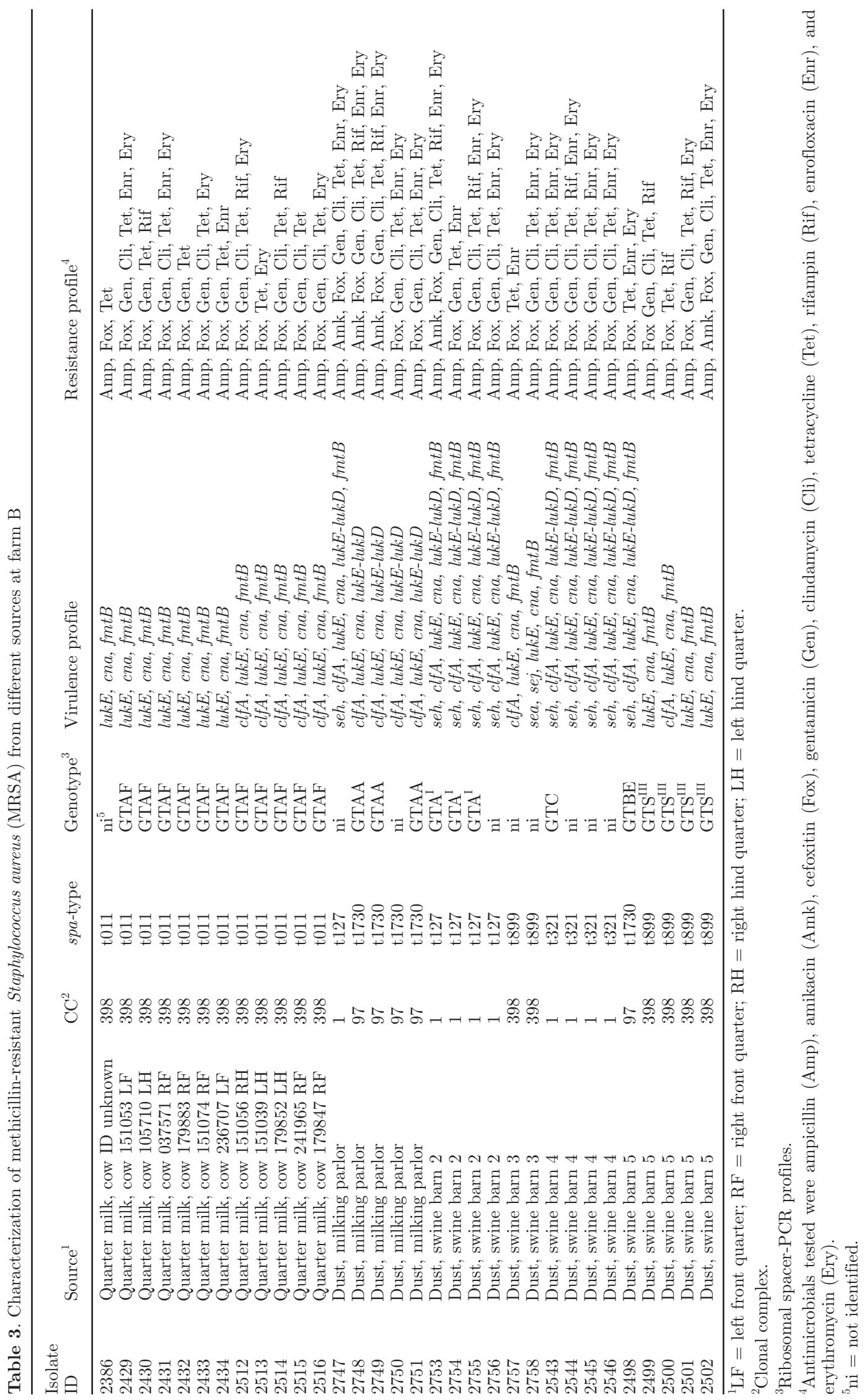


the dust samples collected from the swine barn 3, tested positive for sea and sej enterotoxin genes. All but 15 CC398 MRSA were positive for the clfA gene. Most isolates carried the $f m t b$ gene, with the exception of 10 CC97 isolates. All isolates tested positive for $l u k E$ and cna genes. All MRSA isolates were negative for the exfoliative toxin A and B genes, for tsst, for the $L u k F / S-P V$ and the $c h p$ genes.

Regarding the antimicrobial resistance phenotype, all the isolates were resistant not only to the $\beta$-lactams tested, but also to tetracycline. Regarding aminoglycosides, 18.8 and $57.8 \%$ of the isolates were resistant to amikacin and gentamicin, respectively. Resistance to fluoroquinolones (enrofloxacin) was $70.3 \%$, whereas erythromycin-resistance was found in $65.6 \%$ of the tested isolates.

Farm A. Two different CC, CC97 (spa-types t1730 and t4795) and CC398 spa-type t899, were detected irrespective of the sampled source (Table 2). The most represented genotype was GTBE $(\mathrm{n}=18)$, which corresponded to the CC97; GTBE included isolates from milk samples $(\mathrm{n}=10)$, isolates from the swine compartment $(\mathrm{n}=1$ from dust samples of the swine barns and $\mathrm{n}=4$ from swine nasal swabs), and 3 isolates from the nasal swab of the owner 2. Eleven CC398 isolates out of 13 belonged to the GTS ${ }^{\mathrm{III}}$ genotype. These latter were detected from swine nasal swabs $(\mathrm{n}=4)$, from the dust sample of a swine barn $(\mathrm{n}=1)$, from the nasal swab of the owner $1(\mathrm{n}=5)$ and from a milk sample (n $=1$ ). One CC398 MRSA (isolate 2402), isolated from the nasal swab of the owner 1, was identified as GTL2.

Farm B. Milk samples were only positive for CC398 t011 MRSA, whereas 3 different CC (CC1, CC97, and CC398) and 4 different spa-types (t321, t1730, t127, and t899) were identified among the MRSA isolates detected from swine barn dust samples. The CC398 t011 isolates were associated with GTAF, the most represented genotype $(\mathrm{n}=11)$; GTAF was identified in 11 out of 12 isolates from milk samples, but not from other sources. The CC1 t127 MRSA were isolated from dust samples collected from both the milking parlor and from the swine barn 2, whereas CC1 t321 was only isolated from dust samples collected from the swine barn 4. The CC97 t1730 was only found in dust samples collected from the milking parlor facilities, with 3 out of 4 isolates identified as GTAA. This latter genotype was not found in any other sample. Isolate 2498 from the swine barn 5 was the only one belonging to the GTBE genotype. Similar to farm A, genotype GTS ${ }^{\mathrm{III}}$ was associated with CC398 t899, but in this case it was detected only in dust samples from swine barns $(\mathrm{n}=$ 4) and not in cow milk samples. Genotypes $\operatorname{GTA}^{\mathrm{I}}(\mathrm{n}=$ $3)$, GTC $(\mathrm{n}=1)$, and other 6 isolates classified as ni and belonging to 2 different clusters were identified in dust samples collected from the swine barns, denoting a noteworthy heterogeneity.

\section{DISCUSSION}

Our study represents the first molecular epidemiologic investigation carried out in Italy on the genetic relatedness of MRSA isolated from dairy farms and closely related swine holdings. Molecular characterization of MRSA isolated from milk, swine, and environmental samples collected in the 2 investigated farms confirmed that CC398 (t899), CC97 (t4795 and t1730), and CC1 (t127) represent the main LA-MRSA lineages in dairy cattle (Alba et al., 2015; Feltrin et al., 2015; Luini et al., 2015) and swine farms (Franco et al., 2011; Alba et al., 2015; Feltrin et al., 2015; Normanno et al., 2015) in Italy. Our study also confirmed the heterogeneity of MRSA lineages circulating in livestock animals in Italy (Battisti et al., 2010; Alba et al., 2015; Feltrin et al., 2015). Conversely, only MRSA isolates belonging to CC398 and a few related spa-types were identified in a similar study performed in the Netherlands (Feßler et al., 2012).

On farm A most of the isolates from quarter milk samples belonged to CC97 t4795 (GTBE), also found in bulk tank milk samples, thus representing the dominant lineage. In this farm, MRSA-positive dairy cows were only $4.8 \%$ and it is noteworthy that Cremonesi et al. (2015) included GTBE among the genotypes found in dairy herds with low prevalence of $S$. aureus. The 2 MRSA isolates that caused CM in 2008 on farm A belonged to CC97 t1730; at genotyping, these isolates clustered with those obtained from milk samples collected 2 yr later, denoting the MRSA capacity to persist $2 \mathrm{yr}$ later at the farm level (Figure 1). Regarding the human isolates, owner 1 harbored CC398 t899, whereas owner 2 carried CC97 t4795, lineages already identified in livestock in Italy (Battisti et al., 2010; Feltrin et al., 2015). It is interesting to note that in farm A CC97 t4795 (GTBE) and CC398 t899 (GTS ${ }^{\mathrm{III}}$ ) were not only detected in milk and human samples, but also in swine nasal swabs and from swine barns dust samples, indicating a probable widespread circulation of these strains at farm level; therefore, possible MRSA transmission from animals to humans (or vice versa) can be hypothesized. Potential zoonotic transmission includes direct contact between farm workers and animals or indirect exposure through the farm environment. In this regard, the negativity for MRSA of the employee milker might be due to the reduced time of his MRSA exposure, as he usually had contact only with cows for milking procedures. A recent study (Bos et al., 2014) stressed the importance of the number of working hours in barns with positive animals for human MRSA exposure. In 
this regard, the adoption of hygienic measures, such as using appropriate personal protective equipment such as face masks and gloves, can be also crucial (van Cleef et al., 2011, 2015; Dufour et al., 2012).

On farm B the estimated MRSA herd prevalence was $60 \%$, much higher than those reported in previous studies on dairy cattle, ranging from 0 to $29 \%$ (Vanderhaeghen et al., 2010; Schlotter et al., 2014; Luini et al., 2015). In this farm, CC398 t011, genotype GTAF, was the only MRSA lineage isolated from milk. The milk MRSA isolates showed a similar virulence pattern (Table 2) and at genotyping clustered together, exhibiting a similarity of $86.8 \%$ (Figure 1), which suggested a contagious route of transmission. In this regard, Schlotter et al. (2014) reported that a single MRSA strain could circulate within a dairy herd. Despite the negativity for MRSA of all the nasal swabs from both the dairy cows and the owners, the high MRSA prevalence in quarter milk samples on farm B could be explained by the very poor hygiene of the milking routines, with milking of the animals and handling of potentially contaminated tools performed without using gloves by the milkers.

Although both farm B owners tested negative for MRSA, a transient MRSA colonization cannot be excluded, as they might have been sampled in a moment of MRSA clearance. In this regard, the demonstrated contamination of the environment could lead to a continuous source of MRSA exposure for workers and farmers without necessarily resulting in a permanent colonization (Wendlandt et al., 2013). The CC398 was the only lineage isolated from different sources in farm B; however, CC398 MRSA from milk belonged to spatype t011 and GTAF, whereas those from the swine barns dust samples belonged to t899 and were identified as $\mathrm{GTS}^{\mathrm{III}}$. A cluster with a similarity of $82.3 \%$ gathered all the CC398 isolates, whereas 2 distinct clusters, with a similarity of 86.8 and $95.2 \%$, respectively, grouped as GTAF and GTS ${ }^{\text {III }}$. The cluster harboring the GTS ${ }^{\text {III }}$ MRSA from swine dust samples in farm B also comprised MRSA from milk, human swabs, swine swabs, and environmental dust samples of farm A, denoting a wide circulation of this lineage within and among farms.

Conversely, CC97 t1730 isolates were detected only in the dust samples from the milking parlor and from the swine barn 5, but not in milk. Isolates of MRSA CC97 from the milking parlor mostly belonged to GTAA and clustered together, with a similarity of $83.5 \%$. Moreover, they showed a similarity of $74 \%$ with the CC97 GTBE isolates detected in farm A from milk, human, and swine nasal swabs, and from environmental dust samples in both farms, grouped in a heterogeneous cluster and showing a similarity of $79.2 \%$. These findings suggest that GTAA isolates, though absent in quarter milk samples, were substantially related to MRSA widely spread in the studied farms and potentially able to cause IMI. Therefore, as suggested by Capurro et al. (2010), the environment could represent an important source of udder infection for healthy cows during milking.

It is interesting to note that, in both farms, a high heterogeneity of MRSA CC, spa-types, or genotypes was observed, although higher in farm B than in farm A (Tables 2 and 3 ). This could be explained by the fact that farm B was related to a finishing swine holding hosting successive batches of animals, potentially coming from different swine farms and possibly carrying different MRSA lineages. The coexistence of different MRSA lineages could additionally favor the exchange and the spread of virulence and resistance determinants among them (Battisti et al., 2010). That could explain a certain variability observed among isolates, especially concerning the resistance patterns (Tables 2 and 3).

We might hypothesize that lactating cows in farm A were exposed, especially during milking, to different strains carried by the owners, accidentally causing IMI. In this case, the use of gloves might have limited the spread of the GTBE MRSA, keeping the intraherd prevalence relatively low. Conversely, in farm B the milkers did not use gloves, which is considered an important tool for the prevention of the diffusion of contagious pathogens from cow to cow (Dufour et al., 2012), and this could explain the high MRSA prevalence rate. Beside the hygienic milking procedures implemented, the highly different prevalence rates observed in the 2 studied herds might also depend on other factors, such as the MRSA CC involved as well as environmental and other farm- or animal-management factors.

In our study, MRSA was isolated from a variety of sources, suggesting the possibility of different colonization or infection patterns for cows. Molecular characterization and comparison of the isolates in each area sampled also suggested the existence of an active and dynamic sharing of MRSA lineages or genotypes between different species and within and between farm facilities or units through direct contact or through the environment. In this regard, it is known that environmental contamination can play an important role in dissemination and maintenance of MRSA strains over time. Methicillin-resistant $S$. aureus is a nasal colonizer of pigs, but does not represent a sanitary problem in swine industry; on the other hand, MRSA can cause IMI and CM in dairy cows (Feßler et al., 2010) and the zoonotic risk for humans (consumers and workers) must be considered (Feltrin et al., 2015). For these reasons, a safe distance between different livestock species facilities would be advisable, with a special regard to swine (Locatelli et al., 2016). Clearly, it is not conceivable 
to move a farm away from another in field conditions. Nevertheless, biosecurity and management practices should be strictly implemented within the farms to prevent the spreading of the infection and host species jumps (Feltrin et al., 2015).

\section{CONCLUSIONS}

Our findings confirm the zoonotic potential of LAMRSA and underline the importance of applying biosecurity measures and good hygiene practices to prevent MRSA spread at farm level. The risk of transmission between swine and related dairy cattle herds should also be considered. A cost-effective policy in dairy cattle farms would consist of preventing MRSA colonization or IMI by enforcing the same measures implemented for the $S$. aureus control, particularly focusing on the hygienic milking procedures and on the application of strict biosecurity measures.

\section{ACKNOWLEDGMENTS}

This work is a part of the project "Survey on the risk factors related to the spreading of antimicrobial resistance in production animals" that Università degli Studi di Milano funded as a postdoctoral grant. Thanks to Frank Welcome from Cornell University (Ithaca, NY) for English text revision

\section{REFERENCES}

Alba, P., F. Feltrin, G. Cordaro, M. C. Porrero, B. Kraushaar, M. A. Argudín, S. Nykäsenoja, M. Monaco, M. Stegger, F. M. Aarestrup, P. Butaye, A. Franco, and A. Battisti. 2015. Livestock-associated methicillin resistant and methicillin susceptible Staphylococcus aureus sequence type (CC) 1 in European farmed animals: High genetic relatedness of isolates from Italian cattle herds and humans. PLoS One 10:e0137143.

Baron, F., M. F. Cochet, J. L. Pellerin, N. Ben Zakour, A. Lebon, A Navarro, I. Proudy, Y. Le Loir, and M. Gautier. 2004. Development of a PCR test to differentiate between Staphylococcus aureus and Staphylococcus intermedius. J. Food Prot. 67:2302-2305.

Battisti, A., A. Franco, G. Merialdi, H. Hasman, M. Iurescia, R. Lorenzetti, F. Feltrin, M. Zini, and F. M. Aarestrup. 2010. Heterogeneity among methicillin-resistant Staphylococcus aureus from Italian swine finishing holdings. Vet. Microbiol. 142:361-366.

Bos, M. E., K. M. Verstappen, B. A. van Cleef, W. Dohmen, A. Dorado-García, H. Graveland, B. Duim, J. A. Wagenaar, J. A Kluytmans, and D. J. Heederik. 2014. Transmission through air as a possible route of exposure for MRSA. J. Expo. Sci. Environ. Epidemiol. 26:263-269. https://doi.org/10.1038/jes.2014.85.

Capurro, A., A. Aspán, and H. Ericsson. Unnerstad, K. Persson Waller, and K. Artursson. 2010. Identification of potential sources of Staphylococcus aureus in herds with mastitis problems. J. Dairy Sci. 93:180-191.

Carfora, V., G. Giacinti, D. Sagrafoli, N. Marri, G. Giangolini, P. Alba, F. Feltrin, L. Sorbara, R. Amoruso, A. Caprioli, S. Amatiste, and A. Battisti. 2016. Methicillin-resistant and methicillin-susceptible Staphylococcus aureus in dairy sheep and in-contact humans: An intra-farm study. J. Dairy Sci. 99:4251-4258.
CLSI. 2013a. M02-A11 AND M100-S23. Performance Standards for Antimicrobial Disk Susceptibility Tests; Approved Standard - Eleventh Edition \& Performance Standards for Antimicrobial Susceptibility Testing; Twenty-Third Informational Supplement. Clinical and Laboratory Standard Institute (CLSI), Wayne, PA.

CLSI. 2013b. VET01-A4 and VET01-S2 - Performance Standards for Antimicrobial Disk and Dilution Susceptibility Tests for Bacterial Isolated from Animals; Approved Standard-Fourth Edition and Supplement, VET01A4E and VET01S2E. CLSI, Wayne, PA.

Corrente, M., G. Normanno, V. Martella, A. L. Bellacicco, N. C. Quaglia, A. Dambrosio, D. Buonavoglia, M. D'Abramo, and C. Buonavoglia. 2007. Comparison of methods for the detection of methicillin resistance in Staphylococcus aureus isolates from food products. Lett. Appl. Microbiol. 45:535-539.

Cortimiglia, C., V. Bianchini, A. Franco, A. Caprioli, A. Battisti, L. Colombo, K. Stradiotto, F. Vezzoli, and M. Luini. 2015. Short communication: Prevalence of Staphylococcus aureus and methicillin-resistant $S$. aureus in bulk tank milk from dairy goat farms in Northern Italy. J. Dairy Sci. 98:2307-2311.

Cremonesi, P., F. Pozzi, M. Raschetti, G. Bignoli, E. Capra, H. U. Graber, F. Vezzoli, R. Piccinini, B. Bertasi, S. Biffani, B. Castiglioni, and M. Luini. 2015. Genomic characteristics of Staphylococcus aureus strains associated with high within-herd prevalence of intramammary infections in dairy cows. J. Dairy Sci. 98:6828-6838.

Cremonesi, P., T. Zottola, C. Locatelli, C. Pollera, B. Castiglioni, L. Scaccabarozzi, and P. Moroni. 2013. Identification of virulence factors in 16S-23S rRNA intergenic spacer genotyped Staphylococcus aureus isolated from water buffaloes and small ruminants. J. Dairy Sci. 96:7666-7674.

Dufour, S., I. R. Dohoo, H. W. Barkema, L. Descôteaux, T. J. Devries, K. K. Reyher, J. P. Roy, and D. T. Scholl. 2012. Manageable risk factors associated with the lactational incidence, elimination, and prevalence of Staphylococcus aureus intramammary infections in dairy cows. J. Dairy Sci. 95:1283-1300.

EFSA. 2010. Scientific report of EFSA. Analysis of the baseline survey on the prevalence of methicillin-resistant Staphylococcus aureus (MRSA) in holdings with breeding pigs, in the EU, 2008. Part B: Factor associated with MRSA contamination of holdings. EFSA J. 8:1597.

Feltrin, F., P. Alba, B. Kraushaar, A. Ianzano, M. A. Argudín, P. Di Matteo, M. C. Porrero, F. M. Aarestrup, P. Butaye, A. Franco, and A. Battisti. 2015. A livestock-associated, multidrug-resistant, methicillin-resistant Staphylococcus aureus clonal complex 97 lineage spreading in dairy cattle and pigs in Italy. Appl. Environ. Microbiol. 82:816-821.

Feßler, A. T., R. G. M. Olde Riekerink, A. Rothkamp, K. Kadlec, O. C. Sampimon, T. J. G. M. Lam, and S. Schwarz. 2012. Characterization of methicillin-resistant Staphylococcus aureus CC398 obtained from humans and animals on dairy farms. Vet. Microbiol. 160:77-84

Feßler, A., C. Scott, K. Kadlec, R. Eiricht, S. Monecke, and S. Schwarz. 2010. Characterization of methicillin-resistant Staphylococcus aureus ST398 from cases of bovine mastitis. J. Antimicrob. Chemother. 65:619-625.

Fournier, C., P. Kuhnert, J. Frey, R. Miserez, M. Kirchhofer, T. Kaufmann, A. Steiner, and H. U. Graber. 2008. Bovine Staphylococcus aureus: Association of virulence genes, genotypes and clinical outcome. Res. Vet. Sci. 85:439-448.

Franco, A., H. Hasman, M. Iurescia, R. Lorenzetti, M. Stegger, A Pantosti, F. Feltrin, A. Ianzano, M. C. Porrero, M. Liapi, and A. Battisti. 2011. Molecular characterization of spa type t127, sequence type 1 methicillin-resistant Staphylococcus aureus from swine. J. Antimicrob. Chemother. 66:1231-1235.

Friese, A., J. Schulz, L. Hoehle, A. Fetsch, B. A. Tenhagen, J. Hartung, and U. Roesler. 2012. Occurrence of MRSA in air and housing environment of swine barns. Vet. Microbiol. 158:129-135.

Haran, K. P., S. M. Godden, D. Boxrud, S. Jawahir, J. B. Bender, and S. Sreevatsan. 2012. Prevalence and characterization of Staphylococcus aureus, including Methicillin-Resistant Staphylococcus aureus, isolated from bulk tank milk from Minnesota dairy farms. J. Clin. Microbiol. 50:688-695. 
Kluytmans, J. A. 2010. Methicillin-resistant Staphylococcus aureus in food products: cause for concern or case for complacency? Clin. Microbiol. Infect. 16:11-15.

Kreausukon, K., A. Fetsch, B. Kraushaar, K. Alt, K. Müller, V. Krömker, K.-H. Zessin, A. Käsbohrer, and B.-A. Tenhagen. 2012. Prevalence, antimicrobial resistance, and molecular characterization of methicillin-resistant Staphylococcus aureus from bulk tank milk of dairy herds. J. Dairy Sci. 95:4382-4388.

Locatelli, C., P. Cremonesi, L. Bertocchi, M. G. Zanoni, A. Barberio, I. Drigo, G. Varisco, B. Castiglioni, V. Bronzo, and P. Moroni. 2016. Short communication: Methicillin-resistant Staphylococcus aureus in bulk tank milk of dairy cows and effect of swine population density. J. Dairy Sci. 99:2151-2156.

Lozano, C., C. Aspiroz, A. I. Ezpeleta, E. Gómez-Sanz, M. Zarazaga, and C. Torres. 2011. Empyema caused by MRSA ST398 with atypical resistance profile, Spain. Emerg. Infect. Dis. 17:138-140.

Luini, M., P. Cremonesi, G. Magro, V. Bianchini, G. Minozzi, B. Castiglioni, and R. Piccinini. 2015. Short communication: Methicillinresistant Staphylococcus aureus (MRSA) is associated with low within-herd prevalence of intra-mammary infections in dairy cows: Genotyping of isolates. Vet. Microbiol. 178:270-274.

Merialdi, G., E. Galletti, S. Guazzetti, C. Rosignoli, G. Alborali, A. Battisti, A. Franco, P. Bonilauri, G. Rugna, and P. Martelli. 2013. Environmental methicillin-resistant Staphylococcus aureus contamination in pig herds in relation to the productive phase and application of cleaning and disinfection. Res. Vet. Sci. 94:425-427.

Murakami, K., W. Minamide, K. Wada, E. Nakamura, H. Teraoka, and S. Watanabe. 1991. Identification of methicillin-resistant strains of staphylococci by polymerase chain reaction. J. Clin. Microbiol. 29:2240-2244.

National Mastitis Council. 1999. Laboratory and Field Handbook on Bovine Mastitis. National Mastitis Council, Madison WI.

Normanno, G., A. Dambrosio, V. Lorusso, G. Samoilis, P. Di Taranto, and A. Parisi. 2015. Methicillin-resistant Staphylococcus aureus (MRSA) in slaughtered pigs and abattoir workers in Italy. Food Microbiol. 51:51-56.

Paterson, G. K., J. Larsen, E. M. Harrison, A. R. Larsen, F. J. Morgan, S. J. Peacock, J. Parkhill, R. N. Zadoks, and M. A. Holmes. 2012. First detection of livestock-associated methicillin-resistant Staphylococcus aureus CC398 in bulk tank milk in the United Kingdom. Euro Surveill. 17:20337.

Schlotter, K., R. Huber-Schlenstedt, A. Gangl, H. Hotzel, S. Monecke, E. Müller, A. Reißig, S. Proft, and R. Ehricht. 2014. Multiple cases of methicillin-resistant CC130 Staphylococcus aureus harboring mecC in milk and swab samples from a Bavarian dairy herd. J. Dairy Sci. 97:2782-2788.

Soavi, L., R. Stellini, L. Signorini, B. Antonini, P. Pedroni, L. Zanetti, B. Milanesi, A. Pantosti, A. Matteelli, A. Pan, and G. Carosi.
2010. Methicillin-resistant Staphylococcus aureus ST398, Italy. Emerg. Infect. Dis. 16:346-348.

Spohr, M., J. Rau, A. Friedrich, G. Klittich, A. Fetsch, B. Guerra, J. A. Hammerl, and B.-A. Tenhagen. 2011. Methicillin-resistant Staphylococcus aureus (MRSA) in three dairy herds in southwest Germany. Zoonoses Public Health 58:252-261.

Stegger, M., J. A. Lindsay, A. Moodley, R. Skov, E. M. Broens, and L. Guardabassi. 2011. Rapid PCR detection of Staphylococcus aureus clonal complex 398 by targeting the restriction-modification system carrying sau1-hsdS1. J. Clin. Microbiol. 49:732-734.

Syring, C., R. Boss, M. Reist, M. Bodmer, J. Hummerjohann, P. Gehrig, and H. U. Graber. 2012. Bovine mastitis: The diagnostic properties of a PCR-based assay to monitor the Staphylococcus aureus genotype B status of a herd, using bulk tank milk. J. Dairy Sci. 95:3674-3682.

van Cleef, B. A., B. H. van Benthem, E. J. Verkade, M. M. van Rijen, M. F. Kluytmans-van den Bergh, H. Graveland, T. Bosch, K. M. Verstappen, J. A. Wagenaar, M. E. Bos, D. Heederik, and J. A. Kluytmans. 2015. Livestock-associated MRSA in household members of pig farmers: Transmission and dynamics of carriage, a prospective cohort study. PLoS One 10:e0127190.

van Cleef, B. A. G. L., H. Graveland, A. P. J. Haenen, A. W. van de Giessen, D. Heederik, J. A. Wagenaar, and J. A. J. W. Kluutmans. 2011. Persistence of livestock-associated methicillin-resistant Staphylococcus aureus in field workers after short-term occupational exposure to swine and veal calves. J. Clin. Microbiol. 49:1030-1033.

Van den Broek, I. V., B. A. G. L. van Cleef, A. Haenen, E. M. Broens, P. J. van der Wolf, M. J. M. van den Broek, X. W. Huijsdens, J. A. J. W. Kluytmans, A. W. van de Giessen, and E. W. Tiemersma. 2009. Methicillin-resistant Staphylococcus aureus in people living and working in swine farms. Epidemiol. Infect. 137:700-708.

van Loo, I., X. Huijsdens, E. Tiemersma, A. de Neeling, N. van de Sande-Bruinsma, D. Beaujean, A. Voss, and J. Kluytmans. 2007. Emergence of methicillin-resistant Staphylococcus aureus of animal origin in humans. Emerg. Infect. Dis. 13:1834-1839.

Vanderhaeghen, W., T. Cerpentier, C. Adriaensen, J. Vicca, K. Hermans, and P. Butaye. 2010. Methicillin-resistant Staphylococcus aureus (MRSA) ST398 associated with clinical and subclinical mastitis in Belgian cows. Vet. Microbiol. 144:166-171.

Voss, A., F. Loeffen, J. Bakker, C. Klaassen, and M. Wulf. 2005. Methicillin-resistant Staphylococcus aureus in Swine Farming. Emerg. Infect. Dis. 11:1965-1966.

Wendlandt, S., K. Kadlec, A. T. Fessler, D. Mevius, A. van EssenZandbergen, P. D. Hengeveld, T. Bosch, L. Schouls, S. Schwarz, and E. van Duijkeren. 2013. Transmission of methicillin-resistant Staphylococcus aureus isolates on broiler farms. Vet. Microbiol. 167:632-637. 